\title{
Morphological and Genetic Diversity of Two Forms of Muksun Coregonus muksun (Salmonidae) of the Khatanga River Basin as a Key for Understanding the Phylogenetic Relationships between Muksun and Whitefish $C$. lavaretus
}

\author{
E. A. Borovikova ${ }^{a, b}, *$ and Yu. V. Budin ${ }^{c, d}$ \\ a Papanin Institute for Biology of Inland Waters-IBIW RAS, Borok, Russia \\ ${ }^{b}$ Institute of Biophysics, Siberian Branch of Russian Academy of Sciences-IBP RAS, Krasnoyarsk, Russia \\ ${ }^{c}$ Krasnoyarsk Branch of All-Russian Scientific Research Institute of Fisheries and Oceanography, Krasnoyarsk, Russia \\ ${ }^{d}$ Krasnoyarsk State Agrarian University, Krasnoyarsk, Russia \\ *e-mail: elena.ibiw@gmail.com
}

Received December 26, 2019; revised February 6, 2020; accepted February 6, 2020

\begin{abstract}
Morphological analysis of muksun Coregonus muksun of the Khatanga River basin revealed that along with its typical high-density-rakered form, individuals of the low-density-rakered form also live in this region. Analysis of the genetic polymorphism of three marker regions of mitochondrial (ND1 and COI fragments) and nuclear (ITS1) DNA indicates the polyphyletic origin of these forms. The revealed low level of genetic differentiation of muksun and whitefish $C$. lavaretus, along with the available data on the absence of clear diagnostic species characteristics, suggest that they belong to the same biological species C. lavaretus.
\end{abstract}

Keywords: muksun Coregonus muksun, low-density-rakered form, high-density-rakered form, morphology, mitochondrial DNA, ITS1, phylogeny, Khatanga River

DOI: $10.1134 / \mathrm{S} 0032945220060016$

\section{INTRODUCTION}

Muksun Coregonus muksun is a species of the subfamily Coregoninae (Salmonidae) abundant and widespread in Siberia. The morphology, ecology, and population structure of muksun as the main component of ichthyocenosis in almost all waterbodies of the North have been studied in quite good detail (Berg, 1948; Kirillov, 1972; Reshetnikov, 1980). A number of ichthyologists note that in northern waterbodies numerous forms of muksun exist: low-density-rakered, high-density-rakered, large-mouthed forms, etc. (Aleksandrova and Kuznetsov, 1968, 1972; Kirillov, 1972; Dormidontov, 1974; Romanov, 1999). The morphological diversity of this species could indicate a high degree of its adaptation to environmental conditions, which manifests itself in different ways: in life expectancy, time of sexual maturation, size and sex compositions of populations, fertility and feeding modes.

Despite the fact that muksun biology in many large waterbodies of the North and their systems is studied quite well, the data for this species from the Khatanga Bay basin are very scarce. In rare publications, muksun of this region was considered only as the main object of fishing and was never the subject of a special study of the features of its morphology and ecology (Mikhin,
1941; Podlesnyi, 1947; Berg, 1948; Lukyanchikov, 1967). It is worth noting that in all published papers, muksun of the Khatanga River basin is referred to as a population represented by a single, widespread form with a large number of gill rakers. Over the past 50 years, targeted ichthyological research in the Khatanga region was not carried out. Rare publications are not very informative and are limited only to a description of the habitat conditions of muksun, some indicators of the structure of its populations, as well as the characteristics of fishing in the Khatanga basin (Bogdanov and Bogdanova, 1999, 2003, 2006).

The goal of the present paper is to study the features of morphology of muksun C. muksun of the Khatanga River basin and to assess the level of morphological diversity of its population. In addition, for the first time for muksun of this region the analysis of genetic polymorphism using various molecular-genetic markers was carried out.

\section{MATERIALS AND METHODS}

The Khatanga River is a middle-sized affluent river in the eastern part of the Taimyr Peninsula. The river length is $227 \mathrm{~km}$. It is formed by the confluence of two 
Table 1. Size of the Khatanga River muksun Coregonus muksun samples analyzed applying various of molecular-genetic techniques

\begin{tabular}{l|c|c|c|c}
\hline \multirow{2}{*}{ Muksun form } & \multirow{2}{*}{ PCR-RFLP analysis } & \multicolumn{3}{c}{ Sequencing } \\
\cline { 3 - 5 } & & ND1 & COI & ITS1 \\
\hline Low-density-rakered & 18 & 11 & 12 & 7 \\
High-density-rakered & 45 & 15 & 22 & 14 \\
Total & 63 & 26 & 12 & 7 \\
\hline
\end{tabular}

PCR-RFLP analysis-polymerase chain reaction with restriction fragment length polymorphism.

rivers: Kheta $(604 \mathrm{~km})$ and Kotui $(1409 \mathrm{~km})$. In the Khatanga River system following sections are distinguished: riverine section, delta, guba (estuary) and bay. The river flows through the North Siberian lowland in a wide valley, has many branches, and there are a large number of islands in the riverbed. The height of the right bank of the river reaches $40 \mathrm{~m}$, while the left bank is predominantly low and only closer to the Khatanga Guba it becomes more pronounced (Resursy ..., 1964).

The fish sampled in 2013-2014 in the Khatanga River section situated at the distance of $20-25 \mathrm{~km}$ from its source, served as the materials for the present study (Fig. 1). The sampling was performed during the fish spawning migration. The fish were sampled using 25 to 85 meters-long gill nets (height of 3 and $6 \mathrm{~m}, 50-$ $65 \mathrm{~mm}$ mesh size). The nets were placed along both river banks at the depths from 5 to $25 \mathrm{~m}$. The nets were checked once a day in a daytime.

Totally 42 fish specimens (17 males and 25 females) were analyzed morphologically. The variability of nine meristic and 25 plastic features were studied (Pravdin, 1966; Romanov et al., 2012). The following designations were used: $F L$-fork length; $D, A, P, V$-number of rays in the dorsal, anal, pectoral and ventral fins; $l l-$ number of perforated scales in the lateral line; sp.br.-number of gill rakers in the $1^{\text {st }}$ gill arch; vert.number of vertebrae sans urostyle. Mathematical and statistical data processing followed commonlyaccepted routine (Mayr et al., 1956; Pravdin, 1966; Lakin, 1980). Statistical significance of differences in the values of morphological features in compared forms of muksun was assessed using Student's $t$-test at $p \leq 0.05$.

For genetic analysis, we analyzed samples of white muscles of 63 individuals caught in the river that were fixed in $96 \%$ ethanol (tissue-to-alcohol ratio $1: 5$ ). These fish were caught in the Khatanga in 2016-2017 in the same area as for the study of morphology. The sample includes representatives of low-density-rakered (18 ind.) and high-density-rakered (45 ind.) forms. For comparison, the analysis includes a sample of muksun (13 specimens) from Pyasina River collected in 2017.

The total genomic DNA was isolated using the DNA-Extran-2 kit (Syntol, Russia). Initially, genetic polymorphism of the sample of muksun of the Khatanga River was assessed by PCR-RFLP analysis (polymerase chain reaction with restriction fragment length polymorphism) of a 2052 base pair (bp) mitochondrial DNA (mtDNA) region containing the gene for the $1^{\text {st }}$ subunit of the NADH-dehydrogenase complex (ND1 fragment). The technique for this analysis was described in detail earlier (Borovikova and Malina, 2018). The significance of the differences between the low-density-rakered and high-densityrakered forms of muksun in terms of the frequencies of composite haplotypes, as determined by PCR-RFLP analysis, was assessed using Pearson's $\chi^{2}$ test (Ivanter and Korosov, 2003). Then, two regions of mtDNA were sequenced: the ND1 fragment and the fragment of the cytochrome oxidase subunit 1 (COI) gene, which is a tool for barcoding the species. In addition, the polymorphism of the nuclear DNA marker (nDNA), the first internal transcribed rDNA spacer (ITS1), was investigated. Samples for sequencing were taken considering the results of PCR-RFLP analysis: samples with composite haplotypes identified in both forms, and samples with haplotypes unique for each form were collected. The amount of material analyzed using different methods of molecular-genetic analysis and using various markers is given in Table 1 .

To determine the nucleotide sequence of the ND1 fragment of mtDNA, PCR products were synthesized using four pairs of primers, as described by Bochkarev et al. (2011). However, in some cases, it was not possible to obtain a high-quality PCR product using the primers proposed by these authors. This is why the synthesis was carried out using primers designed by us specifically for this work. Thus, instead of primer ND1pr3Rv 5'-GCG TAT TTA TGA GGA GAT GTT-3' we used primer ND1-3rv-whf 5'-GCG TAT TTA TGA GGA GGA TGT T-3'; instead of primer ND1pr4Fr 5'-ACT AGT CTC TGG GTT TAA TGT AGA A-3', primer ND1-4fw-whf 5'-GAA CTA GTC TCT GGT TTT AAT GTA G-3'. Amplification of the COI gene region was performed using the Fish-F1 and Fish-R1 primers (Ward et al., 2005), as described earlier (Borovikova et al., 2016).

To synthesize the ITS1 rDNA fragment, we used primers MD-1 (direct), 5'-CTT GAC TAT CTA GAG GAA GT-3' and 28S (reverse) 5'-ATA TGC TTA AAT 


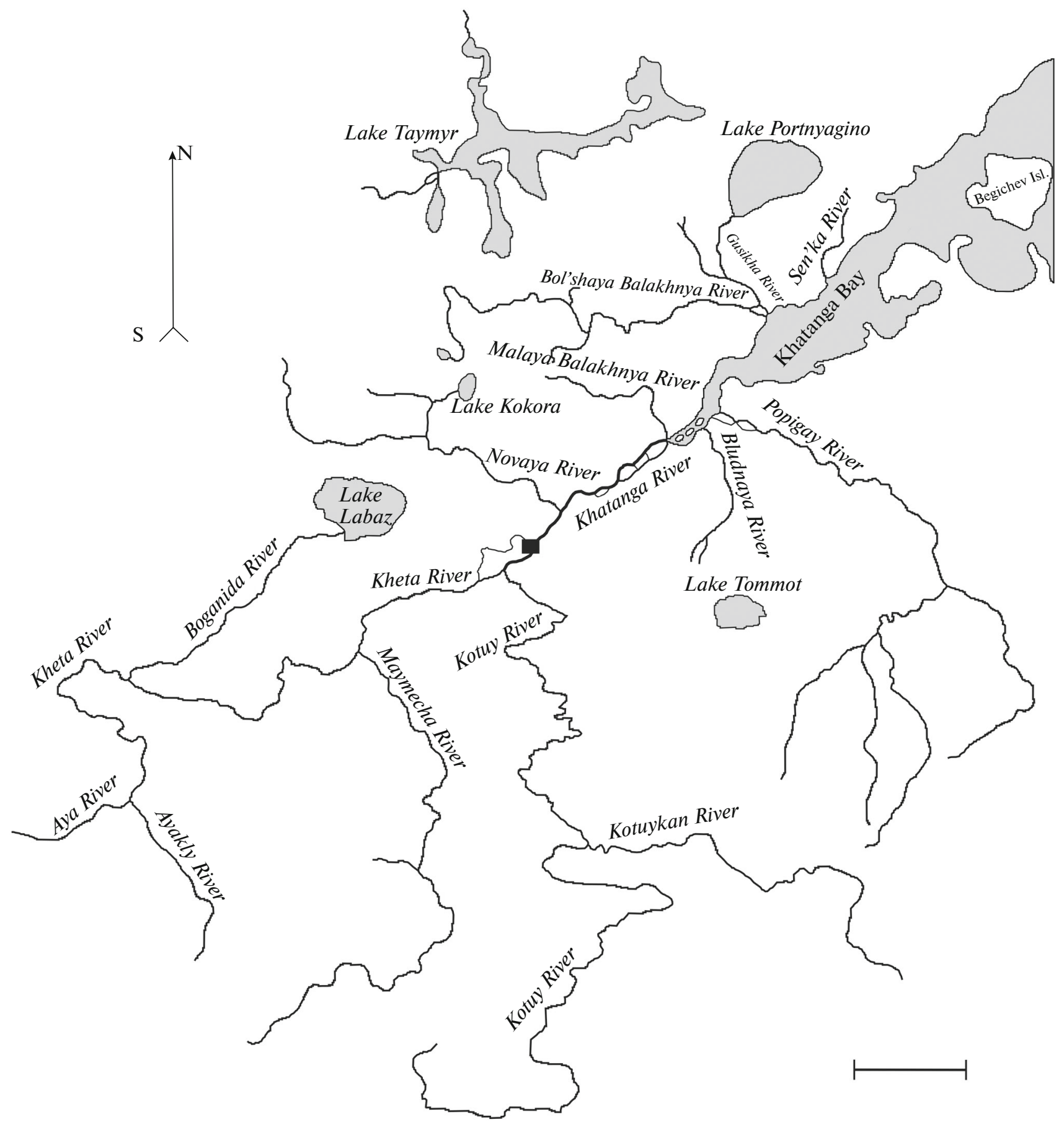

Fig. 1. Schematic map of the Khatanga River basin: (घ)-location of catching muksun Coregonus muksun. Scale: $50 \mathrm{~km}$.

TCA GCG GG-3' (Sajdak and Phillips, 1997). The reaction mixture with a volume of $20 \mu \mathrm{L}$ contained: $2 \mu \mathrm{L}$ of 10-fold buffer for amplification (SibEnzyme Ltd., Russia); $0.6 \mu \mathrm{L}$ of $50 \mathrm{mM} \mathrm{MgCl}_{2}$ (final concentration in the mixture $1.7 \mathrm{mM}), 200 \mathrm{nmol}$ of each of the four deoxyribonucleotides, $0.5 \mathrm{mM}$ of each primer, 0.75 activity units of Taq-DNA polymerase (SibEnzyme Ltd., Russia) and 100-300 ng of total cell DNA.
To prevent evaporation during PCR mineral oil was layered a top of the mixture. The amplification program included the following stages: initial denaturation at $94^{\circ} \mathrm{C}$ for $5 \mathrm{~min} ; 36$ cycles: $94^{\circ} \mathrm{C}-1 \min 30 \mathrm{~s}$, $50^{\circ} \mathrm{C}-2 \mathrm{~min}, 72^{\circ} \mathrm{C}-3 \mathrm{~min}$; the final elongation stage at $72^{\circ} \mathrm{C}$ for $10 \mathrm{~min}$ (Sajdak and Phillips, 1997, with modification). The resulting PCR product was used for sequencing from primers KP2 (direct) 5'-AAA 
AAG CTT CCG TAG GTG AAC CTG CG-3' and 5.8S (reverse) 5'-AGC TTG GTG CGT TCT TCA TCG A-3' (Sajdak and Phillips, 1997). In all cases, before sequencing, the PCR product was purified by direct re-precipitation with a mixture of ethanol and ammonium acetate (http://www.genome-centre.ru/ downloads/NH4Ac_EtOH.pdf).

Sequencing was carried out at IBIW RAS using the BigDye Terminator v. 3.1 Cycle Sequencing Kit (Applied Biosystems, United States) on an ABI 3500 automatic analyzer (Applied Biosystems, Hitachi, Japan) according to the manufacturer's recommendations.

For the analysis of polymorphism of nucleotide sequences the MEGA6 program (Tamura et al., 2013) and DnaSP v. 5 (Librado and Rozas, 2009) software packages were used. Since the lengths of the sequences obtained during the sequencing varied due to the different quality of the DNA samples, only that part of the sequences that was presented in all samples was used for program processing and analysis of the results obtained. For instance, for the ND1 fragment, the length of the analyzed region was $1863 \mathrm{bp}$. In the fulllength mitochondrial genome of whitefish $C$. lavaretus (NCBI number AB034824), the fragment analyzed by us is located in the 2063-3925 bp region. The length of the fragment of the COI gene, which was used for the analysis of polymorphism, is $494 \mathrm{bp}$; a fragment is located between 5651 and $6144 \mathrm{bp}$ of $C$. lavaretus genome (NCBI number AB034824). The length of the ITS 1 region considered by us after sequence alignment was 568 and $634 \mathrm{bp}$, respectively, for options without and with insertion.

In addition to the sequences of the ND1 fragment obtained in the present study, during analysis we used whitefish sequences from GenBank (http://www. ncbi.nlm.nih.gov/genbank. Version 10/2019) under the numbers KM013424, KP123652, KP123653, KP123658, KP123662, KX010455, MG251330, MG251341, MN047157; muksun-KX151797, KX151801, KX151803; least cisco C. sardinellaKT267306; Arctic cisco C. autumnalis-KJ767526, KJ767527; nelma Stenodus leucichthys_KX151784.

For the comparison the sequences given in GenBank were also used when assessing the level of $C O I$ polymorphism: for whitefish from different water bodies of Europe and Siberia, AB034824, JQ661382JQ661397，JQ661419-JQ661481，JX960897， and MN047157; for least cisco, KT267305. The analysis of the polymorphism of the ITS1 fragment included whitefish sequences numbered AJ417728, AJ417729, KJ742924, KJ742925, KP184423, and KR376138. In addition, when constructing haplotype networks, we used whitefish sequences from a number of Siberian and European waterbodies and muksun from artificially maintained populations that are available in our database, but not deposited in NCBI.

To assess the degree of differentiation of haplotypes, their groups, intra- and interpopulation, as well as interspecies differentiation, the $p$-distance (the average number of nucleotide substitutions per site) was calculated using the MEGA6 software. The standard error for $p$-distance was calculated using the bootstrap procedure (500 replications). When calculating the $p$-distance, both in the case of the ND1 fragment and COI, the Kimura's two parameter model (Kimura, 1980) determined in the same program was used as the model of nucleotide substitutions.

To draw the median networks of the ND1 fragment and $C O I$ haplotypes, we used the Network 5.0.1.0 program with the following settings: $\varepsilon=0$, the significance level for all substitutions was 10, the ratio of transitions and transversions was $1: 1$, neither insertions nor deletions in the studied fragments (Bandelt et al., 1999). In some cases, in order to determine and refine the composite haplotypes of mtDNA ND1 fragment sequenced by us, their virtual restriction was carried out using the online resource RestrictionMapper, version 3 (http://www.restrictionmapper.org. Version 11/2019).

The variants of the muksun sequences of the Khatanga and Pyasina rivers that we identified during the present study were deposited in the NCBI database under the following numbers: for the ND1 fragment, MN689096-MN689110, MN701618, MN701619, MN722637-MN722639; for COI, MN689111; for ITS1-MN661339, MN661340.

\section{RESULTS}

\section{Specific Features of Morphology of Low-Density-Rakered and High-Density-Rakered Forms of Muksun}

The analysis of the present study materials indicates that in the Khatanga River basin two forms of muksun present: low-density-rakered and high-density-rakered.

High-density-rakered form: $D$ IIIIV 10-13 (11.6 on average), $A$ III-IV 10-13 (11.7), P 13-16 (14.5), V 9-12 (10.1), sp.br. 55-70 (60.4), ll 86-100 (94.2), vert. 60-62 (61.1). The mouth is inferior, the snout is blunt and elongated. The skull narrows in front, large upper jaw noticeably overhangs over the mandible. The snout is wide, the width of the snout tip area is two-fold larger than its height. The head is long (20.4-27.8\% FL), low. The back is darkgrey, body sides silver-white, ventral side of body is light in color, scales are large, firmly attached.

Low-density-rakered form: $D$ IIIIV 10-13 (11.4), $A$ III-IV 10-12 (11.5), P 13-15 (14.3), $V$ 10-11 (10.1), sp.br. 30-48 (42.9), ll 83-98 (90.0), vert. 64-65 (64.4). Differs from the high-density-rakered form by shortened and higher body, short mandible and higher snout tip area. The head is short, high, the hump is well visible behind the head. Body sides and ventral side of body are golden-yellow.

In general, there are no clearly pronounced differences in the external morphology of the two forms of 
muksun. When comparing the average values of nine meristic parameters for statistically significant samples of low-density-rakered and high-density-rakered forms of muksun, significant differentiation was revealed for three parameters (Table 2). In the highdensity-rakered form, in comparison with the lowdensity-rakered one, the values of $l l(t=3.77)$ and sp.br. $(t=13.3)$ are larger, but of vert. $(t=14.2)$ is smaller. Out of 30 plastic features, the differences were noted for 11 ones. The most significant differentiation was found in the proportions of the head and the size of the fins: the high-density-rakered muksun is characterized by a long and low head, a lower body height, and short pectoral and ventral fins.

\section{Genetic Polymorphism of Muksun Population}

PCR-RFLP analysis of the mtDNA ND1 fragment revealed in the sample of muksun from the Khatanga River 10 composite haplotypes, three of them (P3, Hat1, and Hat2) are common for high-density-rakered and low-density-rakered forms (Table 3). It is worth noting that the composite haplotype P3 is widespread not only in muksun, but also in Siberian whitefish (Politov et al., 2000, 2004; Baldina et al., 2008).

Two unique haplotypes (CM18 and CM34) were described for the low-density-rakered muksun, while five (CM11, CM13, CM16, CM22, and CM24), for the high-density-rakered. It is important the samples of the high-density-rakered and low-density-rakered muksun significantly differ $(p \leq 0.05)$ in composite haplotypes' frequencies (Table 3): in the low-densityrakered muksun, the composite haplotype Hat 2 has a higher frequency of occurrence, while the Hat 1 haplotype is more common in representatives of the highdensity-rakered form. At the same time, the frequencies of unique haplotypes and common haplotype P3 in the high-density-rakered and low-density-rakered muksun differ insignificantly. The haplotype diversity $(H)$ in both forms is approximately the same: 0.68 in the high-density-rakered form and 0.71 in the lowdensity-rakered form. For comparison: in the sample of muksun from the Pyasina River, in terms of occurrence frequency, variant $\mathrm{P} 3$ prevails; haplotype diversity in this sample is low $(H=0.16)$.

Taking into account the data of PCR-RFLP analysis, the carriers of common composite haplotypes P3, Hat1, and Hat2 were selected among low-densityrakered and high-density-rakered forms for sequencing of the mtDNA ND1 fragment. In addition, the carriers of unique haplotypes were included in the analysis. In the representatives of both forms, 17 sequence variants were identified, information about which was deposited in the NCBI database (see numbers in Table 3). The length of the revealed sequences of the ND1 fragment vary from 1961 to $2051 \mathrm{bp}$. The sequencing results confirmed the previously noted limitations of the information obtained on the genetic diversity of the population using PCR-RFLP analysis
(Borovikova and Makhrov, 2009a). For instance, within the composite haplotype P3 in the muksun of the Khatanga and Pyasina rivers, the sequencing method revealed eight variants of sequences (P3-1-P3-8); two sequences are described for the composite haplotype CM18 (CM18-1 and CM18-2) (Table 3).

Since a number of composite haplotypes detected by PCR-RFLP analysis include several sequence variants, below we will call them "haplogroups", while the sequence variants determined by sequencing as "haplotypes". That is, for low-density-rakered and high-density-rakered forms of muksun, 10 haplogroups (equal to the number of composite haplotypes) were identified, each of which has a different number of haplotypes. The P3 haplogroup includes, as mentioned above, eight haplotypes, the CM18 haplogroup two. The rest of the haplogroups (Hat1, Hat2, CM11, CM13, CM16, CM22, CM24, and CM34) are formed by just one sequence variant, or haplotype.

It is worth noting, that despite the low information value, the PCR-RFLP analysis data on the presence of the same haplotypes for two forms of muksun are correct, as evidenced by the sequencing results: common sequence variants are present within haplogroups P3, Hat 1 and Hat2, although both forms also possess unique options (Table 3 ).

To understand the level of differences between haplogroups and haplotypes of the Khatanga River muksun, an assessment of the genetic differentiation between them was undertaken. It turned out that the most significantly differentiated from the rest of the haplogroups are CM18 and CM22, as well as CM11. Between the variants CM11 and CM22 of the highdensity-rakered form, the maximum values of the $p$-distance $(0.7 \%)$ were noted (Table 4$)$. Differentiation of haplotypes of the low-density-rakered form varies from 0.1 to $0.5 \%$. Within haplogroups, the sequences differ insignificantly: the difference is one to four nucleotides $(p$-distance $=0.1 \%)$. Similar values of $p$-distance between haplotypes were also found for the Pyasina River muksun.

If to consider the level of genetic diversity within the forms, the genetic distances between the haplotypes of the low-density-rakered form are slightly higher than of the high-density-rakered ones: 0.3 and $0.2 \%$, respectively (Table 5). For muksun of the Pyasina River this value is $0.1 \%$.

The differentiation between the forms is $0.3 \%$, while the distance of both forms from the Pyasina River muksun is $0.2 \%$. Comparing to whitefish, the level of differentiation varies within $0.2-0.5 \%$, while with such species as least cisco, Arctic cisco, and nelma, it is $1.9-2.9 \%$.

Analysis of the network of sequence variants of the ND1 fragment of the Khatanga River muksun revealed, firstly, the presence in its low-density-rakered form of the P3-1 haplotype which is common with whitefish (Fig. 2). The sequence variant that we 
Table 2. Morphological features of two forms of the Khatanga River muksun Coregonus muksun

\begin{tabular}{|c|c|c|c|c|c|c|c|c|c|}
\hline \multirow{2}{*}{ Feature } & \multicolumn{4}{|c|}{ High-density-rakered form } & \multicolumn{4}{|c|}{ Low-density-rakered form } & \multirow{2}{*}{$t$} \\
\hline & $\lim$ & $M \pm m$ & $\sigma$ & $n$ & $\lim$ & $M \pm m$ & $\sigma$ & $n$ & \\
\hline$\overline{F L}, \mathrm{~mm}$ & $430-563$ & $512 \pm 6.97$ & & 20 & $392-523$ & $466 \pm 7.76$ & & 22 & \\
\hline$S L, \mathrm{~mm}$ & $410-534$ & $487 \pm 6.60$ & & 20 & $370-496$ & $438 \pm 7.34$ & & 22 & \\
\hline$W, \mathrm{~g}$ & $929-1980$ & $1430 \pm 66.10$ & & 20 & $650-1906$ & $1243 \pm 77.40$ & & 22 & \\
\hline$D_{1}$ & $3-4$ & $3.75 \pm 0.10$ & 0.10 & 20 & $3-4$ & $3.7 \pm 0.10$ & 0.46 & 22 & 0.16 \\
\hline$D_{2}$ & $10-13$ & $11.6 \pm 0.18$ & 0.82 & 20 & $10-13$ & $11.4 \pm 0.15$ & 0.73 & 22 & 0.98 \\
\hline$P$ & $13-16$ & $14.5 \pm 0.15$ & 0.69 & 20 & $13-15$ & $14.3 \pm 0.12$ & 0.57 & 22 & 0.93 \\
\hline$V$ & $9-12$ & $10.1 \pm 0.12$ & 0.55 & 20 & $10-11$ & $10.1 \pm 0.07$ & 0.35 & 22 & 0.25 \\
\hline$A_{1}$ & $3-4$ & $3.25 \pm 0.10$ & 0.44 & 20 & $3-4$ & $3.2 \pm 0.08$ & 0.39 & 22 & 0.52 \\
\hline$A_{2}$ & $10-13$ & $11.7 \pm 0.16$ & 0.73 & 20 & $10-12$ & $11.5 \pm 0.14$ & 0.67 & 22 & 0.92 \\
\hline$l l$ & $86-100$ & $94.2 \pm 0.77$ & 3.42 & 20 & $83-98$ & $90.0 \pm 0.81$ & 3.79 & 22 & 3.77 \\
\hline sp.br. & $55-70$ & $60.4 \pm 0.77$ & 3.45 & 90 & $30-48$ & $42.9 \pm 1.07$ & 5.02 & 90 & 13.30 \\
\hline \multirow[t]{2}{*}{ vert. } & $60-62$ & $61.1 \pm 0.20$ & 0.91 & 20 & $64-65$ & $64.4 \pm 0.10$ & 0.49 & 22 & 14.20 \\
\hline & \multicolumn{9}{|c|}{ As $\%$ of $F L$} \\
\hline$H$ & $18.5-24.3$ & $21.6 \pm 0.38$ & 1.72 & 20 & $18.4-26.5$ & $23.2 \pm 0.40$ & 1.89 & 22 & 2.83 \\
\hline$h$ & $6.1-6.7$ & $6.37 \pm 0.05$ & 0.20 & 20 & $5.94-7.45$ & $6.9 \pm 0.08$ & 0.38 & 22 & 5.18 \\
\hline$a D$ & $40.4-44.1$ & $42.3 \pm 0.23$ & 0.85 & 14 & $36.0-43.6$ & $41.7 \pm 0.45$ & 1.81 & 16 & 1.20 \\
\hline$a V$ & $46.1-49.4$ & $47.9 \pm 0.23$ & 0.86 & 14 & $39.8-48.6$ & $46.5 \pm 0.48$ & 1.91 & 16 & 2.66 \\
\hline$a A$ & $69.2-74.3$ & $71.9 \pm 0.33$ & 1.23 & 14 & $49.2-73.2$ & $69.6 \pm 1.51$ & 6.03 & 16 & 1.50 \\
\hline$p D$ & $40.4-46.1$ & $43.7 \pm 0.41$ & 1.52 & 14 & $39.2-47.0$ & $44.4 \pm 0.49$ & 1.98 & 16 & 1.14 \\
\hline$P-A$ & $11.5-14.8$ & $13.3 \pm 0.20$ & 0.81 & 16 & $12.3-14.9$ & $13.4 \pm 0.15$ & 0.68 & 20 & 0.56 \\
\hline$P-V$ & $25.8-30.8$ & $27.9 \pm 0.30$ & 1.32 & 20 & $23.1-30.8$ & $28.0 \pm 0.33$ & 1.56 & 22 & 0.32 \\
\hline$V-A$ & $24.0-49.4$ & $38.2 \pm 2.51$ & 11.2 & 20 & $24.0-48.6$ & $38.0 \pm 2.15$ & 10.10 & 22 & 0.07 \\
\hline$l D$ & $10.5-13.3$ & $12.0 \pm 0.18$ & 0.79 & 20 & $10.1-13.2$ & $11.6 \pm 0.18$ & 0.83 & 22 & 1.31 \\
\hline$h D$ & $12.7-16.4$ & $14.2 \pm 0.18$ & 0.79 & 20 & $12.7-16.7$ & $14.7 \pm 0.22$ & 1.02 & 22 & 1.85 \\
\hline$l A$ & $8.74-12.1$ & $10.4 \pm 0.18$ & 0.83 & 20 & $8.50-11.9$ & $10.1 \pm 0.15$ & 0.70 & 22 & 1.53 \\
\hline$h A$ & $9.26-11.7$ & $10.4 \pm 0.16$ & 0.73 & 20 & $10.2-13.1$ & $11.2 \pm 0.14$ & 0.68 & 22 & 3.58 \\
\hline$l P$ & $12.8-15.6$ & $14.0 \pm 0.17$ & 0.75 & 20 & $12.3-16.9$ & $14.8 \pm 0.22$ & 1.04 & 22 & 2.74 \\
\hline$l V$ & $12.5-15.2$ & $13.4 \pm 0.15$ & 0.68 & 20 & $10.6-15.7$ & $14.4 \pm 0.26$ & 1.22 & 22 & 3.26 \\
\hline$c$ & $20.4-27.8$ & $22.0 \pm 0.36$ & 1.59 & 20 & $17.5-22.2$ & $20.3 \pm 0.21$ & 1.00 & 22 & 4.12 \\
\hline \multirow[t]{2}{*}{$l$} & $71.7-76.6$ & $74.9 \pm 0.31$ & 1.37 & 20 & $66.7-80.1$ & $75.6 \pm 0.59$ & 2.75 & 22 & 1.04 \\
\hline & \multicolumn{9}{|c|}{ As $\%$ of $c$} \\
\hline ao & $24.6-35.5$ & $31.5 \pm 0.51$ & 2.30 & 20 & $26.0-37.2$ & $30.4 \pm 0.51$ & 2.40 & 22 & 1.53 \\
\hline$o$ & $12.4-34.6$ & $16.3 \pm 1.01$ & 4.51 & 20 & $15.4-17.9$ & $16.6 \pm 0.15$ & 0.69 & 22 & 0.33 \\
\hline po & $46.1-58.5$ & $55.3 \pm 0.59$ & 2.66 & 20 & $48.3-68.5$ & $56.3 \pm 0.77$ & 3.63 & 22 & 1.03 \\
\hline $\operatorname{lm} x$ & $25.1-34.4$ & $30.6 \pm 0.46$ & 2.05 & 20 & $16.9-35.8$ & $30.7 \pm 0.77$ & 3.59 & 22 & 0.09 \\
\hline $\operatorname{lmd}$ & $31.5-47.5$ & $43.1 \pm 0.90$ & 4.04 & 20 & $36.3-43.6$ & $39.2 \pm 0.42$ & 1.98 & 22 & 3.91 \\
\hline$h m x$ & $7.80-13.6$ & $10.2 \pm 0.27$ & 1.22 & 20 & $9.8-13.5$ & $11.4 \pm 0.19$ & 0.91 & 22 & 3.48 \\
\hline$e$ & $16.0-23.5$ & $20.6 \pm 0.41$ & 1.83 & 20 & $16.2-23.0$ & $20.2 \pm 0.41$ & 1.90 & 22 & 0.59 \\
\hline$f$ & $7.60-11.4$ & $8.95 \pm 0.22$ & 1.00 & 20 & $9.5-13.3$ & $10.9 \pm 0.23$ & 1.07 & 22 & 6.18 \\
\hline io & $18.7-36.1$ & $25.0 \pm 0.69$ & 3.06 & 20 & $23.6-28.8$ & $26.2 \pm 0.28$ & 1.30 & 22 & 1.63 \\
\hline$c H$ & $46.9-68.9$ & $60.5 \pm 1.09$ & 4.88 & 20 & $49.9-71.3$ & $64.5 \pm 0.98$ & 4.57 & 22 & 2.72 \\
\hline
\end{tabular}

$F L$-fork length, $S L$-standard length, $l$-body length (from the tip of head to the end of scale cover), $W$-body weight; $D_{1}, D_{2}-$ number of unbranched and branched rays in the dorsal fin; $P, V$-number of branched rays in the pectoral and ventral fins; $A_{1}, A_{2}-$ number of unbranched and branched rays in the anal fin; $l l-$ number of scales in the lateral line, sp.br.-number of gill rakers on the $1^{\text {st }}$ gill arch, vert. - number of vertebrae sans urostyle; $H, h$-largest and smallest body height; $a D, a V, a A, p D, P-A, P-V, V-A-$ antedorsal, anteventral, anteanal, postdorsal, pectroanal, pectroventral, and ventroanal distances; $l D, h D$-base length and height of the dorsal fin; $l A, h A$-same for the anal fin; $l P, l V$-lengths of the pectoral and ventral fins; $c$-length of head, $a o-$ length of snout, $o$-diameter of the eye, $p o$-post-orbital section of the head; $\operatorname{lm} x, \operatorname{lm} d$-lengths of upper jaw and mandible, $h m x$-width of the upper jaw; $e, f$-width and height of snout tip area, io-interorbital distance, $\mathrm{cH}$-height of the head at the level of nape; lim-limits of the parameter variations, $M \pm m$-mean and error of mean, $\sigma$-standard deviation, $n$-number of specimens, ind., $t$-Student's test; bold type marks the parameters of significant differentiation at $p \leq 0.05$. 
Table 3. Frequencies of haplogroups and information on the diversity within them in different forms of muksun Coregonus muksun of the Khatanga and Pyasina rivers

\begin{tabular}{|c|c|c|c|c|c|}
\hline \multirow{3}{*}{$\begin{array}{l}\text { Composite haplotype } \\
\text { (PCR-RFLP), } \\
\text { or haplogroup }\end{array}$} & \multirow{3}{*}{ Haplotype* } & \multirow{3}{*}{ NCBI number } & \multicolumn{3}{|c|}{ Haplogroup frequency, $\%$} \\
\hline & & & \multicolumn{2}{|c|}{ Khatanga River } & \multirow{2}{*}{ Pyasina River } \\
\hline & & & low-density-rakered & high-density-rakered & \\
\hline P3 & $\begin{array}{l}\text { P3-1 } \\
\text { P3-2 } \\
\text { P3-3 } \\
\text { P3-4 } \\
\text { P3-5 } \\
\text { P3-6 } \\
\text { P3-7 } \\
\text { P3-8 }\end{array}$ & $\begin{array}{l}\text { MN689097 } \\
\text { MN722637 } \\
\text { MN689096 } \\
\text { MN689100 } \\
\text { MN689105 } \\
\text { MN689106 } \\
\text { MN689107 } \\
\text { MN689109 } \\
\text { MN722639 }\end{array}$ & $\begin{array}{l}50.0 \\
+ \\
+ \\
+ \\
\\
\\
+ \\
+\end{array}$ & $\begin{array}{l}+ \\
+ \\
+ \\
+\end{array}$ & $\begin{array}{c}92.3 \\
+ \\
+\end{array}$ \\
\hline Hat1 & Hat 1 & MN689108 & 11.1 & 37.8 & \\
\hline Hat2 & Hat2 & MN689110 & 22.2 & 2.2 & \\
\hline CM18 & $\begin{array}{l}\text { CM18-1 } \\
\text { CM18-2 }\end{array}$ & $\begin{array}{l}\text { MN689098 } \\
\text { MN689101 }\end{array}$ & $\begin{array}{c}11.1 \\
+ \\
+\end{array}$ & & \\
\hline CM34 & CM34 & MN689099 & 5.6 & & \\
\hline CM11 & CM11 & MN689102 & & 2.2 & \\
\hline CM13 & CM13 & MN689103 & & 8.9 & \\
\hline CM16 & CM16 & MN689104 & & 2.2 & \\
\hline CM22 & CM22 & MN701618 & & 2.2 & \\
\hline CM24 & CM24 & MN701619 & & 2.2 & \\
\hline CMP117 & CMP117 & MN722638 & & & 7.7 \\
\hline
\end{tabular}

* The variant of mtDNA ND1 fragment determined by the results of sequencing; "+"-the variant of sequence in the group sample is noted.

have identified is identical to the sequence of the Baltic Sea whitefish (NCBI KP123658). Note that the muksun of the Pyasina is characterized by the predominance of carriers of this particular haplotype in the sample (Table 3). It is also important that the four variants of the Khatanga muksun out of 17 turned out to be common to both of its forms (P3-6, P3-7, Hat1, Hat2). Six variants were found to be specific for lowdensity-rakered form (P3-1, P3-2, P3-3, CM18-1, CM18-2, CM34), and seven variants for high-densityrakered one (P3-4, P3-5, CM11, CM13, CM16, CM22, CM24).

Fig. 2 clearly shows that most variants of ND1 sequences in both-forms of muksun originate from the P3-1 variant common to whitefish. With this in mind, three groups of haplotypes may be distinguished. The first group combines variants slightly differentiated from the P3-1 haplotype, from which they originate and which in relation to them can be called ancestral (P3-2, P3-3, P3-4, P3-5, P3-6, P3-7, and Hat1). These variants differ from $\mathrm{P} 3-1$ by one or two nucleotide substitutions. The second group is formed by variants, the differentiation of which from the P3-1 haplotype is somewhat greater (Hat2, CM11, CM13, CM24, and CM34). The third group includes haplotypes significantly differentiated from the P3-1 variant and belonging to other phylogenetic lineages (CM18-1, CM18-2, and CM22). As noted above, their differentiation with the P3-1 variant reaches $0.5 \%$ (Table 4). The Pyasina River muksun is characterized by a similar situation: the CMP117 variant is significantly differentiated from the others found in this sample.

No polymorphism was revealed for the mtDNA COI fragment of Khatanga muksun: all individuals are carriers of the same haplotype, which is widespread in muksun in other waterbodies, as well as in whitefish from Europe and Siberia. For example, this haplotype includes the $C O I$ sequences of whitefish from Danish waterbodies (JQ661390-JQ661397, JQ661423, JQ661424, JQ661432, JQ661433, JQ661435, JQ661438, JQ661439, JQ661442, JQ661444-JQ661449, JQ661451, JQ661453, JQ661457, JQ661460, JQ661468, JQ661472, 


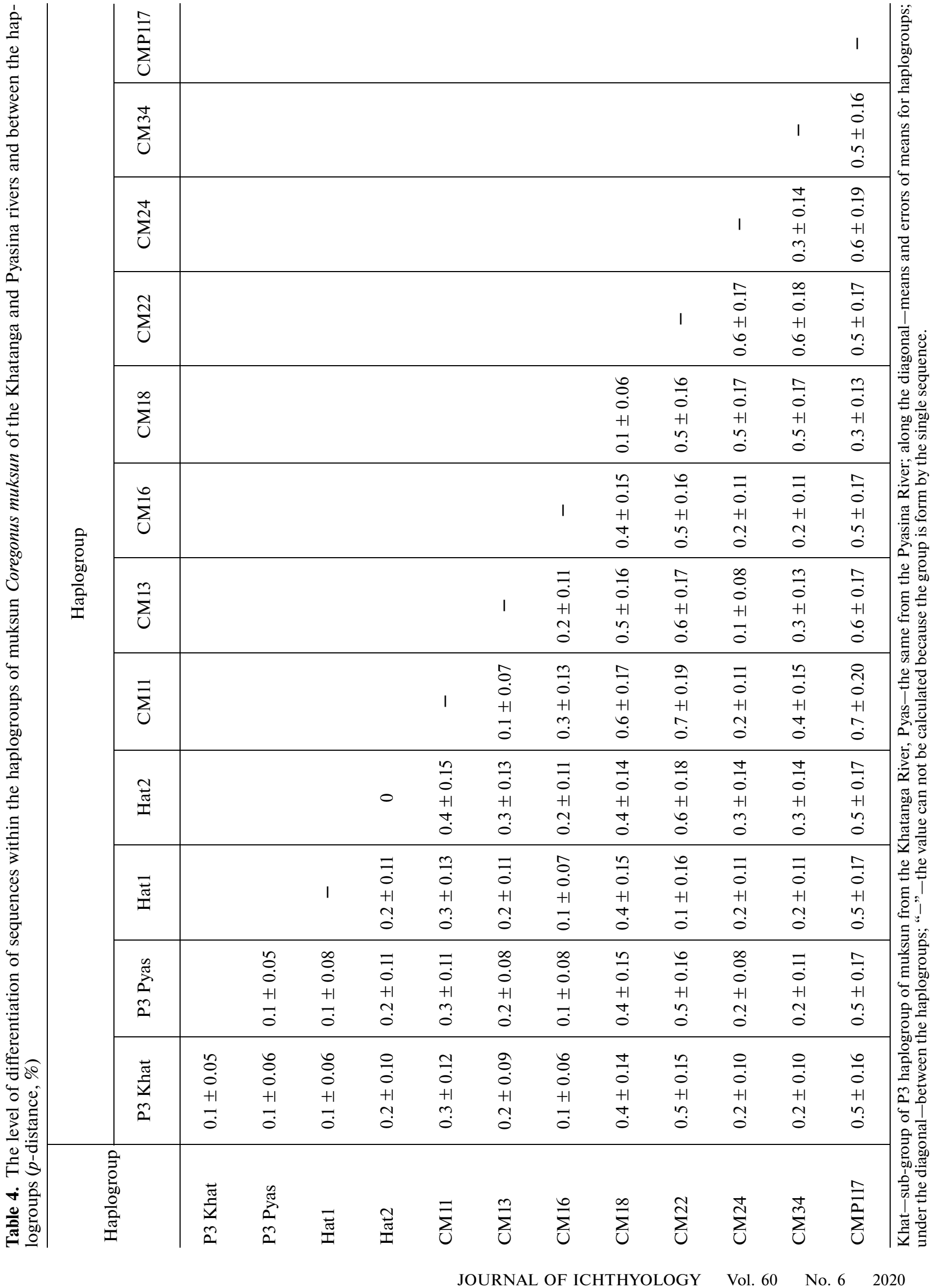




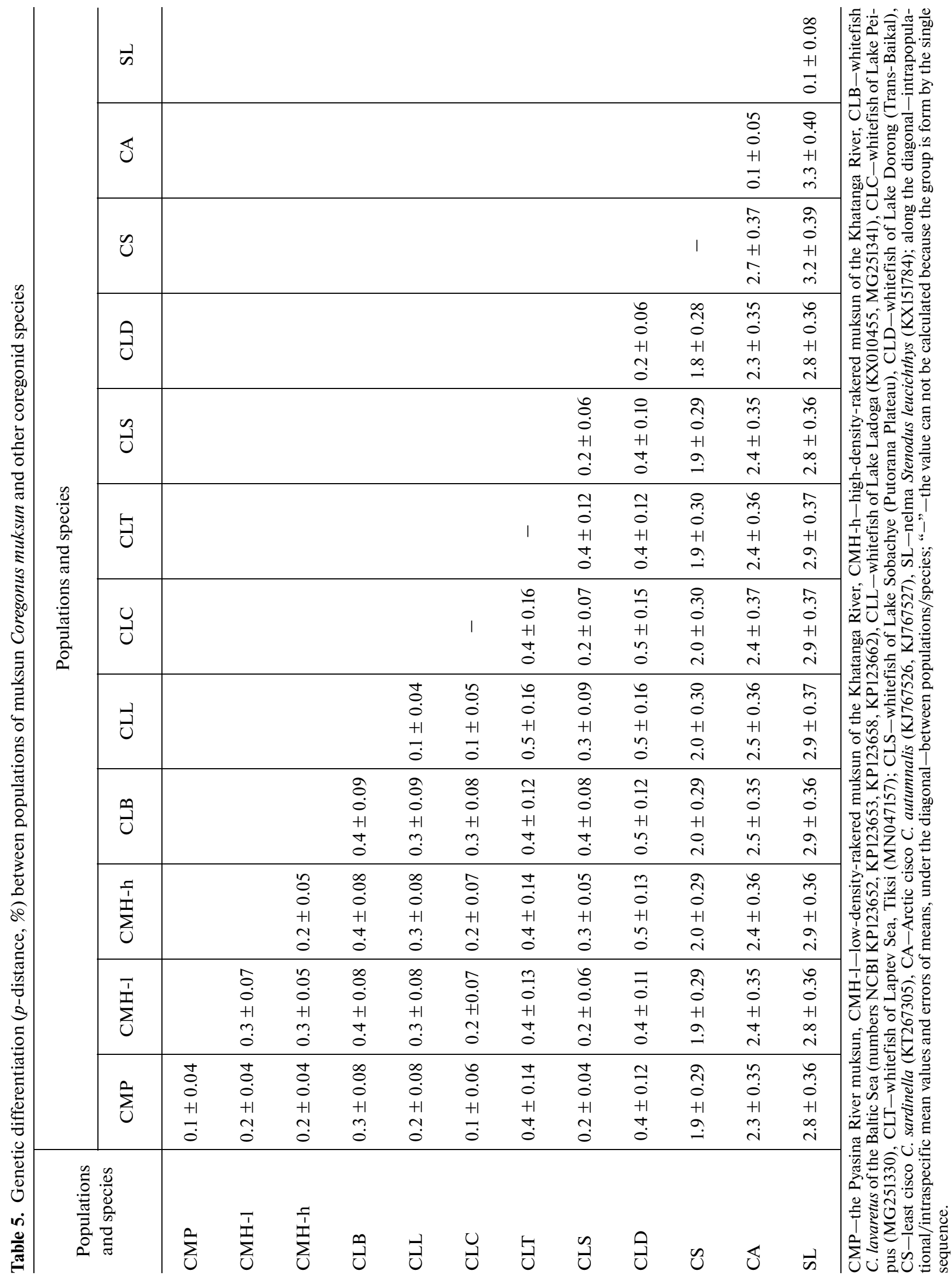




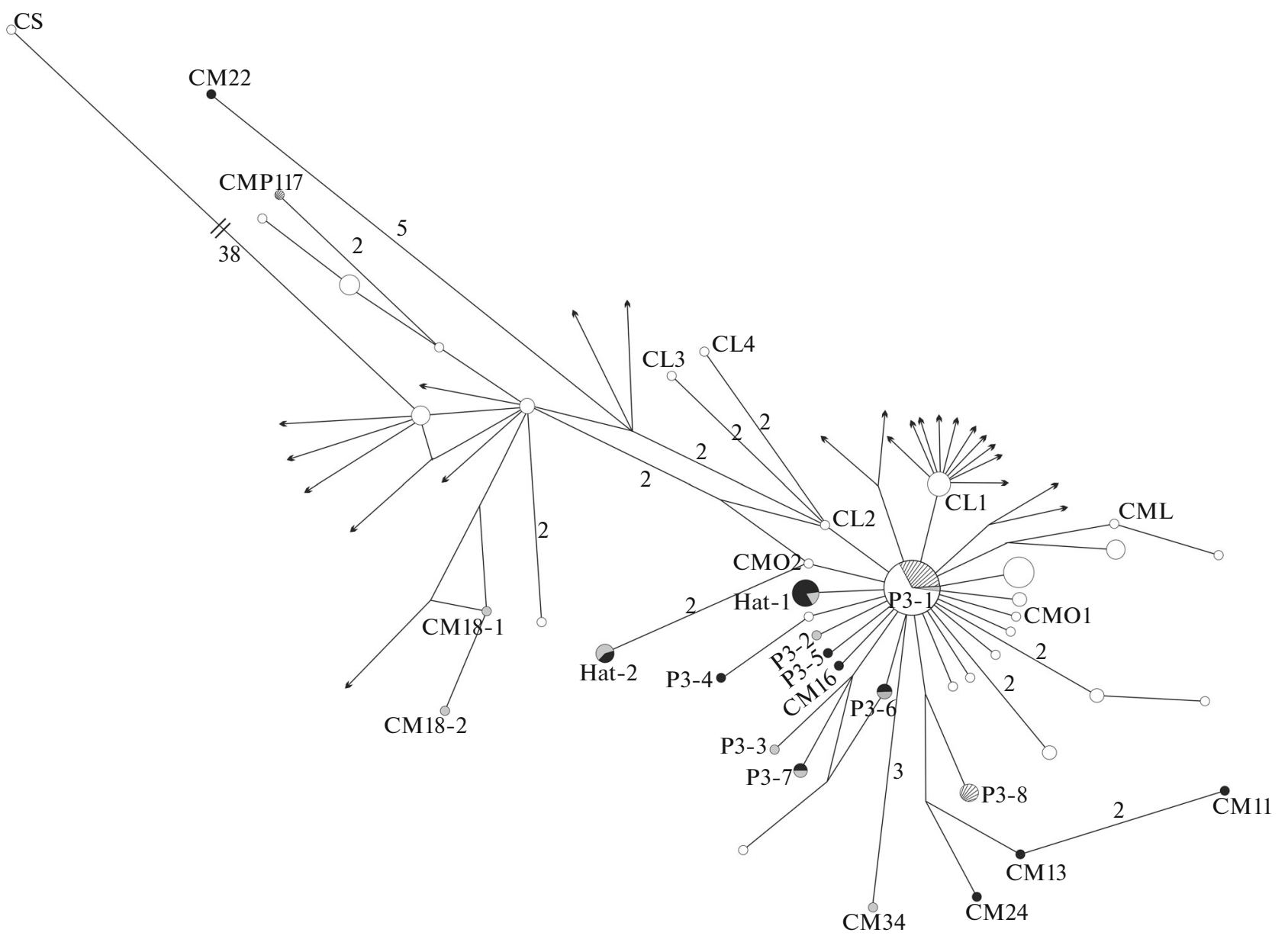

Fig. 2. Network of haplotypes of ND1 fragment of mitochondrial DNA in muksun Coregonus muksun: (ם)-high-density-rakered form of the Khatanga River, ( $\square$ ) - low-density-rakered form of the Khatanga River, ( $\square$ ) - muksun of the Pyasina River, ( $\square$ )-muksun and whitefish C. lavaretus of the waterbodies of Europe and Siberia. At drawing the network we used sequences from GenBank as well as those ones from our own database not deposited in NCBI. P3-1-P3-8, Hat-1, Hat-2, CM11, CM13, CM16, CM18-1, CM18-2, CM22, CM24, CMP117-haplotypes of muksun from Khatanga and Pyasina rivers; CMLmuksun of the Lena River (no. NCBI KX151797), CMO1 and CMO2-muksun of the Ob River (KX151801 and KX151803, respectively), CL1-whitefish of the Baltic Sea (KP123662), Lake Ladoga (KX010455 and MG251341), Lake Peipus (MG251330); CL2 and CL3 - whitefish of the Baltic Sea (KP123652 and KP123653, respectively), CL4-Siberian whitefish C. lavaretus pidschian of the Lena River basin (KM013424), CS-least cisco C. sardinella (KT267306). The sequence of whitefish of the Baltic Sea (KP123658) belongs to the P3-1 variant. The diameter of the circle corresponds to the variant frequency. The number of nucleotide substitutions between the variants is indicated next to the segments connecting them; if the number is not specified, then the distance between the variants is equal to one nucleotide substitution; $(\rightarrow)$-continuation of the network to the haplotypes of whitefish, that do not analyzed in the present study.

JQ661474, JQ661479, JQ661480), the Baltic Sea (JQ661382-JQ661389), and Siberia (JX960897).

Analysis of the polymorphism of the nDNA ITS1 fragment in the Khatanga River muksun revealed variation in the length of this section. In the studied sample, an individual with an ITS1 fragment of $634 \mathrm{bp}$ was found, while the length of the remaining 13 sequences was $568 \mathrm{bp}$. The increase in the fragment size was due to the insertion of $66 \mathrm{bp}$ at the site following the $241^{\text {st }}$ nucleotide of the sequence of whitefish of the Abakan River (KJ742925). It is worth noting that the length and nucleotide sequence of the ITS1 variant with the insertion of muksun of the Khatanga River is identical to the indicated sequence from
GenBank. It is also important that an individual with a long variant of the ITS1 fragment carries a common with whitefish P3-1 ND1 fragment haplotype. These results may be considered as just one more confirmation of the significant genetic similarity and phylogenetic affinity of muksun and whitefish.

There is no polymorphism in the nucleotide sequence of the ITS1 fragment of the Khatanga River muksun.

\section{DISCUSSION}

The number of gill rakers typical for muksun varies within 42-65 (Atlas..., 2003); only in the Norilsk lakes 
Table 6. Variability of the numbers of perforated scales in the lateral line (ll) and gill rakers on the 1st gill arch (sp.br.) in muksun Coregonus muksun of the Khatanga, Pyasina and Taymyra rivers basins

\begin{tabular}{l|l|l|l|l|l|l|l}
\hline \multirow{2}{*}{ Waterbody, form } & \multicolumn{3}{|c|}{$l l$} & \multicolumn{3}{|c|}{$s p . b r}$. & \multirow{2}{*}{ Reference } \\
\cline { 2 - 6 } & \multicolumn{1}{|c|}{$\lim$} & $M$ & $n$ & $\lim$ & $M$ & $n$ & \\
\hline Khatanga River: & $78-104$ & 90.0 & 187 & $39-72$ & 55.0 & 187 & Lukyanchikov, 1962, 1967 \\
- low-density-rakered & $83-98$ & 90.0 & 22 & $30-48$ & 42.9 & 90 & Own data \\
- high-density-rakered & $86-100$ & 94.2 & 22 & $55-70$ & 60.4 & 90 & The same \\
Pyasina River: & & & & & & & \\
- typical & $88-107$ & 93.5 & 28 & $44-65$ & 56.4 & 28 & Ostroumov, 1937 \\
-lacustrine & $82-98$ & 92.0 & 28 & $45-72$ & 59.5 & 28 & The same \\
Lake Melkoye & $83-100$ & 91.7 & 47 & $45-78$ & 64.4 & 47 & Logashev, 1940 \\
Lake Lama & $86-99$ & 92.0 & - & $41-73$ & 59.5 & - & Belykh, 1940 \\
& $84-96$ & 89.2 & 15 & $37-49$ & 43.0 & 15 & Romanov, 1999 \\
Lake Taymyrskoye & $79-98$ & 87.1 & 58 & $60-70$ & 63.5 & 58 & Mikhin, 1955 \\
& $82-94$ & 87.6 & 56 & $(53) 59-75$ & 63.9 & 55 & Romanov, 1999 \\
Verkhnyaya Taymyra River & $82-94$ & 88.8 & 17 & $59-68$ & 62.3 & 7 & The same \\
\hline
\end{tabular}

lim-limits of the parameter variation, $M$-mean, $n$-number of specimens, ind.; “-”-no information.

it reaches 78. However, several authors indicate a wider range of variability of this parameter (Table 6). For instance, in the Khatanga River muksun the value of sp.br. varies within 39-72 (Lukyanchikov, 1967); in muksun from Lake Lama (the Pyasina River basin), 41-73 (Belykh, 1940). Such a significant range of variability in the number of gill rakers in the muksun populations suggested the heterogeneity of the latter. Since the $1970^{\text {th }}$ several researchers note the existence of lowdensity-rakered and high-density-rakered muksun forms that may live sympatrically; in the low-densityrakered form the value of $s p . b r$. averages 36-43 (Aleksandrova and Kuznetsov, 1972; Kirillov, 1972; Dormidontov, 1974; Romanov, 1999; Kostitsin, 2011; Budin and Zadelenov, 2019).

The wide variability of the number of gill rakers of the Khatanga muksun (30-70) assumes two its forms live in the Khatanga River. The analysis of the complex of meristic and plastic parameters really revealed the heterogeneity of the muksun migrating to the river for spawning. Two groups were identified with a clear hiatus for sp.br:: low-density-rakered form (30-48 gill rakers) and high-density-rakered (55-70 gill rakers) (Table 2). Other distinctive features of morphology were also revealed for these two forms: statistically significant differentiation was noted in the number of vertebrae, perforated scales in the lateral line, size of fins, head, and body height. Representatives of two forms are also distinguishable in habitus: the low-density-rakered muksun has a pronounced hump, while the high-density-rakered has a wider snout and a specific body coloration.

It is obvious that the differences in forms concern not only their morphology, but also ecology. Thus, the high-density-rakered and low-density-rakered muksun differ in the feeding area. Brackish waters of the Khatanga River estuary and bay serve as the feeding and wintering area of the high-density-rakered muksun, while individuals of the low-density-rakered form pre- fer the rush of the river. Longer pectoral and ventral fins, which serve as rudders, balancers, brakes, and bearing planes, probably contribute to the stabilization of the tall body of the low-density-rakered muksun in the river water column (Aleev, 1963). In addition, the forms differ in the time of the beginning of spawning migration and the length of the spawning path.

Thus, the above facts confirm the existence of two sympatric forms of muksun in the Khatanga River basin. However, it should be noted, that not all researchers agree with the opinion on the existence of two muksun forms. For example, Reshetnikov (1980, p. 164) is skeptical about the defining of the low-density-rakered form ("... if there really are low-densityrakered forms among the species $C$. muksun (Pallas), then the differences between $C$. lavaretus sensu lato and $C$. muksun practically disappears...") and indicates the need to revise the materials available for two forms (Atlas ..., 2003).

The molecular genetic analysis clarifies the phylogenetic relationships of high-density-rakered and lowdensity-rakered muksun of the Khatanga River, as well as with other species of the g. Coregonus. It also made it possible to specify the origin of these forms in this river's basin. It turned out that the degree of genetic differentiation ( $p$-distance) between the forms is low $(0.3 \%)$ and does not exceed the intraspecific level (Table 5).

It is important that the intrapopulation differentiation of muksun is comparable to the level of differences between it and whitefish: $0.2-0.3$ and $0.2-$ $0.5 \%$, respectively. It is worth noting that the level of differentiation of $0.5 \%$ is also typical for different whitefish populations (Table 5). The phylogenetic relationship of whitefish and muksun is evidenced by the presence of identical, common sequence variants for all three markers of genetic polymorphism used in the present study (ND1 fragment, COI, and ITS1). 
It should be noted that neither morphological characters nor markers of genetic polymorphism making it possible to reliably identify the species $C$. lavaretus and C. muksun have been found so far (Heinonen, 1988; Ermolenko, 1991; Politov et al., 2000, 2002, 2004; Borovikova and Makhrov, 2009b). Moreover, the revealed plasticity and allometry of craniological features of whitefish from the White Sea basin (our data) cast doubt on the validity of $C$. muksun, since morphologically this species differs from common whitefish only in the shape of the skull (Reshetnikov, 1980). There are no clear differences between whitefish and muksun at the level of chromosome sets: the range of variability of the whitefish karyotype includes several variants chromosome sets of muksun (Atlas ..., 2003). It seems likely, that the geographical criterion is not applicable for distinguishing between species, since a number of authors believe that muksun lives not only in Siberia, but also in Europe (Kitaev, 2004; Kottelat and Freyhof, 2007; review: Borovikova and Makhrov, 2013). The set of our results and published data on the absence of clear morpho-ecological, genetic, karyological, and geographical diagnostic features makes it possible, from the point of view of the biological concept of the species, to speak of conspecificity of muksun and whitefish. In the light of the above facts, the assumption by Reshetnikov (1980) about the blurring of the boundaries between these species is confirmed.

Due to the low level of genetic differentiation of C. lavaretus and C. muksun, Baldina et al. (2008) consider different hypotheses for the origin of the latter. However, the point of view according to which whitefish and muksun are conspecific, casts doubt on some of them. In particular, in our opinion, if we consider whitefish and muksun as belonging to the same species, the assumption of these authors about spontaneous periodic hybridization of two "species" as the reason for the appearance of common variants of sequences of different marker DNA regions in these groups, is inappropriate: in this case common origin explains appearance common variants. Even more doubtful is the scenario according to which muksun is the result of hybridization of the Siberian whitefish C. lavaretus pidschian (or a close form) and the representative of the cisco and peled C. peled complex. The authors substantiate the possibility of this phenomenon by the fact that composite haplotypes of least cisco for the mtDNA ND1 fragment were found in the muksun sample. We did not reveal sequence variants common with least cisco for any of the markers we used. Differentiation of muksun haplotypes with the closest variant of the sequence of the ND1 fragment of the least cisco was $2.0 \%$ (Table 5); for COI, $1.8 \%$. It is possible that the data obtained by the authors (Baldina et al., 2008) are due to an error in the identification of species at the sampling.

Consideration of the history of the formation of the population of the muksun in the Khatanga River may be important for understanding the origin of muksun as a group of coregonid fish in general. For instance, the analysis of the genetic variability of the Khatanga muksun indicates its polyphyletic origin (Table 4, Fig. 2). Despite the small amount of analyzed materials, a similar conclusion is also valid for the muksun of the Pyasina River. Indeed, in both populations haplotypes belonging to different phylogenetic lineages may be noted even within one form, which apparently arose in different geographic regions. For example, these are variants CM22 and CM11 in high-densityrakered muksun of the Khatanga River; haplotypes CMP117 and P3-8 of Pyasina muksun (Fig. 2). At the same time, some of the haplotypes of both forms of the Khatanga muksun occurred in the Taimyr Peninsula (variants of haplogroups P3, Hat1, and Hat2) from one ancestral variant (P3-1). It is important to note that the haplotypes currently recorded in the whitefish of the Yenisei River, Lake Sobachye (Putorana Plateau), as well as muksun of the $\mathrm{Ob}$ and Lena rivers also occurred from haplotype P3-1. Variants derived from P3-1 are found even in whitefish populations of the European North: in the White and Baltic seas basins (Fig. 2). Probably, the ancestral carrier form of the P3-1 haplotype was widespread in the water bodies of the Arctic Ocean basin. However, we do not assert that only this phylogenetic lineage was ancestral for all whitefish (including muksun) of this region: analysis of the haplotype network suggests the presence of several large phylogenetic lineages of mtDNA.

It seems worth noting that the polyphyletic origin of the low-density-rakered and high-density-rakered forms of muksun do not allow them to be attributed to different taxa and raise their status even to the level of subspecies, which Kirillov (1972) suggested for the low-density-rakered form. Obviously, independent morphogenesis in different water systems, as in the case of whitefishe of European water bodies is a characteristic of muksun (Østbye et al., 2005).

Thus, according to the data of morphological analysis two forms of muksun inhabit the Khatanga River: typical high-density-rakered and low-density-rakered. The revealed low level of genetic differentiation of muksun and whitefish, along with the available published data, indicates that they belong to the same species-C. lavaretus. In the light of data of the present study, it seems likely that muksun is a form of C. lavaretus with the largest number of gill rakers among the group of whitefish with inferior mouth (subgenus Coregonus s. str.). This fish is widespread in Siberia, and its morphological diversity and genetic polymorphism are determined by polyphyletic origin in different river basins.

The presence of common haplotypes, on the one hand, indicates their divergence from a common ancestor within the study region; on the other hand, each form includes representatives of phylogenetic lineages originating outside of it. It should be noted that 
the possibility of an independent origin of muksun in different regions is also indicated by Baldina et al. (2008), while Kostitsin (2011) considers paleogeographic factors that could lead to partial isolation and diversification of populations in different basins. The subsequent invasion of representatives of different phylogenetic lineages into same basin and even a waterbody, as in the case of vendace $C$. albula from Lake Pleshcheyevo (Borovikova, 2017; Borovikova, and Artamonova, 2018), is well known for coregonids (Hudson et al., 2007).

\section{ACKNOWLEDGMENTS}

We are sincerely grateful to V.V. Sytin (OOO Energiya, Khatanga settlement), V.D. Petrov (United Directorate of Taymyr Natural Reserves, Norilsk), M.P. Poborskii (Firewatch-Rescue Detachment no. 136, Khatanga Settlement), L.A. Glushchenko (Institute of Fundamental Biology and Biotechnology, Krasnoyarsk) and V.P. Prokaev (Norilsk) for help in sampling the materials; to A.A. Makhrov (Severtsov Institute of Ecology and Evolution, Russian Academy of Sciences, Moscow) for discussion of the manuscript and valuable comments.

\section{FUNDING}

The paper is prepared with financial support of the Russian Scientific Foundation, grant no. 16-14-10001.

\section{COMPLIANCE WITH ETHICAL STANDARDS}

Conflict of interests. The authors declare that they have no conflicts of interest.

Statement on the welfare of animals. All applicable international, national, and/or institutional guidelines for the care and use of animals were followed.

\section{OPEN ACCESS}

This article is distributed under the terms of the Creative Commons Attribution 4.0 International Public License (http://creativecommons.org/licenses/by/4.0/), which permits unrestricted use, distribution, and reproduction in any medium provided you give appropriate credit to the original author(s) and the source, provide a link to the Creative Commons license, and indicate if changes were made.

\section{ADDITIONAL INFORMATION}

The publication of this Open Access article was funded by Pleiades Publishing.

\section{REFERENCES}

Aleev, Yu.G., Funktsional'nye osnovy vneshnego stroeniya ryby (Functional Basis of External Morphology of Fishes), Moscow: Akad. Nauk SSSR, 1963.

Aleksandrova, E.N. and Kuznetsov, V.V., The intraspecific forms of muksun Coregonus muksun (Pallas) from the Lena River, Vestn. Mosk. Gos. Univ., 1968, no. 1, pp. 28-37.

Aleksandrova, E.N. and Kuznetsov, V.V., Differentiation of muksun of the Lena River. 1. Morphometric characteristics of four forms of muksun, Vestn. Mosk. Gos. Univ., 1972, no. 4, pp. 8-15.

Atlas presnovodnykh ryb Rossii (Atlas of Freshwater Fishes of Russia), Reshetnikov, Yu.S., Ed., Moscow: Nauka, 2003, vol. 1.

Baldina, S.N., Gordon, N.Yu., and Politov, D.V., Mitochondrial DNA genetic differentiation of the muksun Coregonus muksun (Pallas) and related Siberian species of Coregonus (Coredonidae, Salmoniformes), Russ. J. Genet., 2008, vol. 44, no. 7, pp. 777-785.

Bandelt, H.J., Forster, P., and Röhl, A., Median-joining networks for inferring intraspecific phylogenies, Mol. Biol. Evol., 1999, vol. 16, no. 1, pp. 37-48.

https://doi.org/10.1093/oxfordjournals.molbev.a026036

Belykh, F.I., The Lama Lake and its use for fishery, Tr. Inst. Polyarn. Zemled., Zhivotnovod. Promysl. Khoz., 1940, no. 11, pp. 72-100.

Berg, L.S., Ryby presnykh vod SSSR $i$ sopredel'nykh stran (Freshwater Fishes of USSR and Adjacent Countries), Moscow: Akad. Nauk SSSR, 1948, vol. 1.

Bochkarev, N.A., Zuykova, E.I., and Katokhin, A.V., Morphology and mitochondrial DNA variation of the Siberian whitefish Coregonus lavaretus pidschian (Gmelin) in the upstream water bodies of the $\mathrm{Ob}$ and Yenisei rivers, Evol. Ecol., 2011, vol. 25 , no. 3 , pp. $557-572$.

https://doi.org/10.1007/s10682-010-9437-7

Bogdanov, N.A. and Bogdanova, G.I., The structure of spawning stocks of the least cisco from the Khatanga River, Materialy nauchno-prakticheskoi konferentsii "Problemy $i$ perspektivy ratsional'nogo ispol'zovaniya rybnykh resursov Sibiri" (Proc. Sci.-Pract. Conf. "Problems and Prospects of Rational Use of Fish Resources of Siberia”), Krasnoyarsk: Krasnoyarsk. Gos. Pedagog. Univ., 1999, pp. 26-30.

Bogdanov, N.A. and Bogdanova, G.I., Stocks and fishery of fishes in the Khatanga River basin, in Problemy ispol'zovaniya i okhrany prirodnykh resursov Tsentral'noi Sibiri (Use and Protection of Natural Resources of Central Siberia), Krasnoyarsk: Krasnoyarsk. Nauchno-Issled. Inst. Geol. Miner. Syr'ya, 2003, no. 4, pp. 271-274.

Bogdanov, N.A. and Bogdanova, G.I., Fishery in the Khatanga River basin, Rybn. Khoz. (Moscow), 2006, no. 5, pp. 61-64.

Borovikova, E.A., Special traits of the genetic structure and origin of the population of vendace Coregonus albula of Pleshcheyevo Lake, Biol. Bull. (Moscow), 2017, vol. 44, no. 3, pp. 245-250.

Borovikova, E.A. and Artamonova, V.S., Morphological specificities of vendace (Salmoniformes: Salmonidae: Coregoninae: Coregonus albula) population in Lake Pleshcheyevo (the Volga River basin): relationships of two phylogenetic lineages in a new zone of secondary contact, Org. Diversity Evol., 2018, vol. 18, no. 3, pp. 355-366.

https://doi.org/10.1007/s13127-018-0375-5

Borovikova, E.A. and Makhrov, A.A., Detection of the mitochondrial DNA haplotype characteristic of the least cisco (Coregonus sardinella, Valenciennes, 1848) in the vendace (C. albula, Linnaeus, 1758) population of Vodlozero (the Baltic Sea Basin), Biol. Bull. (Moscow), 2009a, vol. 36, no. 1, pp. 80-83.

Borovikova, E.A. and Makhrov, A.A., Systematic position and origin of European whitefish (Coregonus, Coregonidae, Osteichthyes): genetic approach, Usp. Sovrem. Biol., 2009b, vol. 129, no. 1, pp. 58-66.

Borovikova, E.A. and Makhrov, A.A., Taxonomy and origin of whitefish and ciscoes (Coregonus) in Europe: a morphoe- 
cological approach, Tr. Karel. Nauchn. Tsentra, Ross. Akad. Nauk, Ser. Ekol. Issled., 2013, no. 6, pp. 105-115.

Borovikova, E.A. and Malina, J.I., Phylogeography of common whitefish (Coregonus lavaretus L.) of Northwestern Russia, Contemp. Probl. Ecol., 2018, vol. 11, no. 3, pp. 286-296.

https://doi.org/10.1134/S1995425518030058

Borovikova, E.A., Romanov, V.I., and Nikulina, J.S., Morphological and genetic features of cisco (Coregonidae: Coregonus sp.) from Lake Sobachye (Putorana Plateau), Russ. J. Genet.: Appl. Res., 2018, vol. 8, no. 1, pp. 37-43.

Budin, Yu.V. and Zadelenov, V.A., Morphological diversity of muksun Coregonus muksun (Pallas, 1814) in the Khatanga River basin, Materialy $V$ Mezhdunarodnoi konferentsii "Sovremennoe sostoyanie vodnykh bioresursov" (Proc. V Int. Conf. "Modern Status of Aquatic Bioresources"), Novosibirsk: Novosib. Gos. Agrar. Univ., 2019, pp. 15-19.

Dormidontov, A.S., Muksun in the Lena River: complex of relative forms, Materialy VI Simpoziuma "Biologicheskie problemy Severa," Tezisy dokladov (Proc. VI Symp. "Biological Problems of the North," Abstracts of Papers), Yakutsk: Yakut. Fil., Sib. Otd., Akad. Nauk SSSR, 1974, no. 2, pp. 51-55.

Ermolenko, L.N., Genetic divergence of whitefishes of the genus Coregonus, Genetika, 1991, vol. 27, no. 3, pp. 515-522. Heinonen, M., Taxonomy and genetic variation of whitefish (Coregonus spp.) in Lake Saimaa, Finn. Fish. Res., 1988, vol. 9, pp. 39-47.

Hudson, A.G., Vonlanthen, P., Müller, R., et al., Review: the geography of speciation and adaptive radiation in coregonines, Adv. Limnol., 2007, vol. 60, special issue, pp. 111-146. Ivanter, E.V. and Korosov, A.V., Vvedenie v kolichestvennиуи biologiyu (Introduction into Quantitative Biology), Petrozavodsk: Petrozavodsk. Gos. Univ., 2003.

Kimura, M., A simple method for estimating evolutionary rate of base substitutions through comparative studies of nucleotide sequences, J. Mol. Evol., 1980, vol. 16, no. 2, pp. $111-120$.

Kirillov, F.N., Ryby Yakutii (Fishes of Yakutia), Moscow: Nauka, 1972.

Kitaev, S.P., O skhodstve morfologii, ekologii, kariotipov $i$ yavlenii parallelilizma, divergentsii $i$ konvergentsii u sigovykh $i$ gol'tsov (On Resemblance of Morphology, Ecology, Karyotypes, and the Phenomenon of Parallelism, Divergence and Convergence in Whitefishe and Charr), Petrozavodsk: Karel. Nauchn. Tsentr, Ross. Akad. Nauk, 2004.

Kostitsyn, V.G., Population structure of muksun Coregonus muksun (Pallas) according to meristic features, Vopr. Rybolov., 2011, vol. 12, no. 2 (46), pp. 306-318.

Kottelat, M. and Freyhof, J., Handbook of European Freshwater Fishes, Berlin: Kotellat, Cornol, Freyhof, 2007.

Lakin, G.F., Biometriya (Biometry), Moscow: Vysshaya Shkola, 1980.

Librado, P. and Rozas, J., DnaSP v5: A software for comprehensive analysis of DNA polymorphism data, Bioinformatics, 2009, vol. 25, no. 11, pp. 1451-1452.

https://doi.org/10.1093/bioinformatics/btp187

Logashev, M.V., Ozero Melkoe i ego rybohozyajstvennoe ispol'zovanie (The Melkoye Lake and its use for fishery), $T r$. Inst. Polyarn. Zemled., Zhivotnovod. Promysl. Khoz., 1940, no. 11, pp. 7-71.

Lukyanchikov, F.V., Morfologo-biologicheskaya harakteristika sigovyh ryb $r$. Hatangi (Morphological and biological characteristics of whitefishes from the Khatanga River), Izv. Vost.-Sib. Otd., Geogr. O-va SSSR, 1962, vol. 60, pp. 81-87.
Lukyanchikov, F.V., Ryby sistemy reki Hatangi (Fishes of the Khatanga River basin), Tr. Krasnoyarsk. Otd., Sib. Nauchno-Issled. Inst. Rybn. Khoz., 1967, vol. 9, pp. 11-93.

Mayr, E., Linsley, E.G., and Usinger, R.L., Methods and Principles of Systematic Zoology, New York: McGraw-Hill, 1953.

Mikhin, V.S., Ryby i rybnyj promysel reki Hatangi i Hatangskogo zaliva (Fishes and fishery of the Khatanga River and Khatanga Bay), Tr. Inst. Polyarn. Zemled., Zhivotnovod. Promysl. Khoz., 1941, no. 16, pp. 37-72.

Mikhin, V.S., Ryby ozera Tajmyri Tajmyrskoj guby (Fishes of the Lake Taimyr and Taimyr Bay), Izv. Vses. NauchnoIssled. Inst. Ozern. Rechn. Khoz., 1955, vol. 35, pp. 35-43.

Østbye, K., Bernatchez, L., Næsje, T.F., et al., Evolutionary history of the European whitefish Coregonus lavaretus (L.) species complex as inferred from mtDNA phylogeography and gill-raker numbers, Mol. Ecol., 2005, vol. 14, pp. 43714387.

https://doi.org/10.1111/j.1365-294X.2005.02737.x

Ostroumov, N.A., Ryby i rybnyj promysel $r$. Pyasiny (Fishes and Fishery in the Pyasina River), Tr. Polyarn. Kom., Akad. Nauk SSSR, 1937, vol. 30, pp. 7-114.

Podlesnyi, A.V., Rybnye resursy $r$. Hatangi i ih ispol'zovanie (Fish resources of the Khatanga River and their use), Rybn. Khoz. (Moscow), 1947, no. 7, pp. 31-34.

Politov, D.V., Gordon, N.Yu., Afanasiev, K.I., et al., Identification of palearctic coregonid fish species using mtDNA and allozyme genetic markers, J. Fish Biol., 2000, vol. 57, suppl. A, pp. 51-71.

https://doi.org/10.1111/j.1095-8649.2000.tb02244.x

Politov, D.V., Gordon, N.Yu., and Makhrov, A.A., Genetic identification and taxonomic relationships of six Siberian species of Coregonus, Arch. Hydrobiol. Spec. Issues, Adv. Limnol., 2002, vol. 57, pp. 21-34.

Politov, D.V., Bickham, J.W., and Patton, J.C., Molecular phylogeography of Palearctic and Nearctic ciscoes, Ann. Zool. Fen., 2004, vol. 41, no. 1, pp. 13-23.

Pravdin, I.F., Rukovodstvo po izucheniyu ryb (Guide for Fish Analysis), Moscow: Pishch. Prom-st', 1966.

Reshetnikov, Yu.S., Ekologiya i sistematika sigovykh ryb (Ecology and Systematics of Coregonids), Moscow: Nauka, 1980.

Resursy poverkhnostnykh vod SSSR. Gidrologicheskaya izuchennost'. Tom 16. Angaro-Eniseiskii raion. Vyp. 1. Enisei (Resources of Surface Waters of USSR: Hydrological Characteristics, Vol. 16: Angara-Yenisei Region, No. 1: Yenisei River), Leningrad: Gidrometeoizdat, 1964.

Romanov, V.I., Population structure of muksun (Coregonus muksun (Pallas)) from reservoirs of the Taimyr Peninsula, Vestn. Tomsk. Gos. Univ., 1999, no. 7 (16), pp. 38-43.

Romanov, V.I., Petlina, A.P., and Babkina, I.B., Metody issledovaniya presnovodnykh ryb Sibiri (Methods of Study of Freshwater Fishes of Siberia), Tomsk: Tomsk. Gos. Univ., 2012.

Sajdak, S.L. and Phillips, R.B., Phylogenetic relationships among Coregonus species inferred from the DNA sequence of the first internal transcribed spacer (ITS1) of ribosomal DNA, Can. J. Fish. Aquat. Sci., 1997, vol. 54, no. 4, pp. 1494-1503. Tamura, K., Stecher, G., Peterson, D., et al., MEGA6: molecular evolutionary genetics analysis, version 6.0, Mol. Biol. Evol., 2013, vol. 30, pp. 2725-2729.

https://doi.org/10.1093/molbev/mst 197

Ward, R.D., Zemlak, T.S., Innes, B.H., et al., DNA barcoding Australia's fish species, Philos. Trans. R. Soc., B, 2005, vol. 360, no. 1462, pp. 1847-1857.

https://doi.org/10.1098/rstb.2005.1716

Translated by D. Pavlov 